\title{
Isolamento e perfil de resistência de Candida spp. de animais domésticos e selvagens
}

\author{
Isolation and resistance profile of Candida spp. of domestic and wild animals \\ Aislamiento y perfil de resistencia de Candida spp. de animales domésticos y salvajes
}

Recebido: 21/07/2021 | Revisado: 01/08/2021 | Aceito: 04/08/2021 | Publicado: 10/08/2021

Stéfhano Luís Cândido
ORCID: https://orcid.org/0000-0003-2735-2121
Universidade Federal de Mato Grosso, Brasil
E-mail: stefanobte @ hotmail.com
Isabela de Godoy Menezes
ORCID: https://orcid.org/0000-0003-2577-8719
Universidade Federal de Mato Grosso, Brasil
E-mail: belinhagodoy@ hotmail.com
Luciano Nakazato
ORCID: https://orcid.org/0000-0002-1244-0690
Universidade Federal de Mato Grosso, Brasil
E-mail: lucnaka@ gmail.com
Thais Oliveira Morgado
ORCID: https://orcid.org/0000-0002-2974-3241
Universidade Federal de Mato Grosso, Brasil
E-mail: thaismorgado@gmail.com
Aline Ludwig
ORCID: https://orcid.org/0000-0002-0904-4953
Universidade Federal de Santa Maria, Brasil
E-mail: lineludwig09@gmail.com
Jânio Morais Santurio
ORCID: https://orcid.org/0000-0001-6286-9076
Universidade Federal de Santa Maria, Brasil
E-mail: janio.santurio@gmail.com
Valéria Dutra
ORCID: https://orcid.org/0000-0002-6630-2293
Universidade Federal de Mato Grosso, Brasil
E-mail: valeriadutra.dutra@gmail.com

\section{Resumo}

Candida spp. são leveduras presentes na microbiota de humanos e animais, porém devido a desordens podem se tornar patogênicas causando candidíase. Este estudo objetivou avaliar a diversidade de espécies de Candida em animais domésticos e silvestres e o perfil de susceptibilidade antifúngica. Um total de 79 isolados foram obtidos de animais domésticos $(n=49)$ e animais silvestres $(n=30)$ coletados de 13 diferentes sítios de lesão. Os isolados foram previamente caracterizados morfológica e tintorialmente e a classificação definitiva ocorreu pelo sequenciamento de DNA da região ITS. O perfil de susceptibilidade foi obtido pela técnica de microdiluição em caldo com os antifúngicos: caspofungina, fluconazol, voriconazol, anfotericina B, nistatina e itraconazol. Doze diferentes espécies de Candida foram identificadas, onde $C$. rugosa foi a espécie mais isolada (26\%; 21/79), seguida por $C$. parapsilosis (20\%; 16/79) e C. albicans $(15 \%, 12 / 79)$. O perfil de susceptibilidade foi avaliado em 30 isolados (10 isolados de $C$. glabrata, 10 isolados de C. tropicalis e 10 isolados de C. parapsilosis), resultando em $100 \%$ dos isolados testados resistentes ao itraconazol, porém nenhum deles foi resistente ao voriconazol. Os isolados de C. tropicalis foram resistentes a múltiplos antifúngicos. Esses dados alertam para o problema mundial de resistência a antimicrobianos, agravado pelo aparecimento de cepas resistentes a múltiplos fármacos. Este é o primeiro estudo que verificou a ocorrência e os perfis de resistência de Candida spp. em animais no Estado de Mato Grosso, Centro-oeste, Brasil, demonstrando a necessidade de novos trabalhos para continuidade da compreensão da relação entre estas leveduras e seus hospedeiros.

Palavras-chave: Brasil; Candidíase; Fungo; ITS; Veterinária.

\section{Abstract}

Candida spp. are yeasts present in the microbiota of humans and animals, but due to disorders, they can become pathogenic, causing candidiasis. This study aimed to evaluate the diversity of Candida species in domestic and wild animals and the antifungal susceptibility profile. A total of 79 isolates were obtained from domestic animals $(\mathrm{n}=49)$ and wild animals $(\mathrm{n}=30)$ collected from 13 different injury sites. The isolates were previously characterized morphologically and tinctorial and the definitive classification occurred by DNA sequencing of the ITS region. The broth microdilution technique obtained the susceptibility profile with the antifungal agents: caspofungin, fluconazole, 
voriconazole, amphotericin B, nystatin, and itraconazole. Twelve different Candida species were identified, where $C$. rugosa was the most isolated species $(26 \%, 21 / 79)$, followed by $C$. parapsilosis $(20 \%, 16 / 79)$ and C. albicans $(15 \%$, 12/79). The susceptibility profile was evaluated in 30 isolates (10 isolates of $C$. glabrata, ten of $C$. tropicalis, and ten of $C$. parapsilosis), resulting in $100 \%$ of the tested isolates being resistant to itraconazole. Still, none of them was resistant to voriconazole. Isolates of $C$. tropicalis were resistant to multiple antifungal agents. These data alerted the worldwide problem of antimicrobial resistance, aggravated by the emergence of strains resistant to multiple drugs. This study is the first study that verified the occurrence and resistance profiles of Candida spp. in animals in Mato Grosso State, Midwest, Brazil, encouraging the execution of new works further to understand the relationship between these yeasts and their hosts.

Keywords: Brazil; Candidiasis; Fungus; ITS; Veterinary.

\section{Resumen}

Candida spp. son levaduras presentes en la microbiota de humanos y animales, pero debido a trastornos pueden volverse patógenas causando candidiasis. Este estudio tuvo como objetivo evaluar la diversidad de especies de Candida en animales domésticos y salvajes y el perfil de susceptibilidad antifúngica. Se obtuvieron un total de 79 aislamientos de animales domésticos $(n=49)$ y animales salvajes $(n=30)$ recolectados de 13 sitios diferentes de lesión. Los aislamientos fueron previamente caracterizados morfológica y tintorialmente y la clasificación definitiva ocurrió por secuenciación del DNA de la región ITS. El perfil de susceptibilidad se obtuvo mediante la técnica de microdilución en caldo con los agentes antifúngicos: caspofungina, fluconazol, voriconazol, anfotericina B, nistatina e itraconazol. Se identificaron doce especies diferentes de Candida, donde $C$. rugosa fue la especie más aislada (26\%; 21/79), seguida de $C$. parapsilosis $(20 \% ; 16 / 79)$ y $C$. albicans $(15 \%, 12 / 79)$. El perfil de susceptibilidad se evaluó en 30 aislamientos (10 aislamientos de $C$. glabrata, 10 aislamientos de $C$. tropicalis y 10 aislamientos de $C$. parapsilosis), resultando en $100 \%$ de los aislamientos probados resistentes a itraconazol, pero ninguno de ellos fue resistente a voriconazol. Los aislamientos de $C$. tropicalis fueron resistentes a múltiples agentes antifúngicos. Estos datos alertan sobre el problema mundial de la resistencia a los antimicrobianos, agravado por la aparición de cepas resistentes a múltiples fármacos. Este es el primer estudio que verificó los perfiles de ocurrencia y resistencia de Candida spp. en animales en el estado de Mato Grosso, Medio Oeste de Brasil, lo que demuestra la necesidad de seguir trabajando para comprender mejor la relación entre estas levaduras y sus huéspedes.

Palabras clave: Brasil; Candidiasis; Hongo; ITS; Veterinaria.

\section{Introdução}

As espécies de Candida são leveduras amplamente distribuídas e são consideradas como constituintes da microbiota da pele e das mucosas de humanos e animais. Quando as barreiras físicas e/ou imunológicas do hospedeiro estão comprometidas, essas leveduras comensais aproveitam os fatores de virulência produzidos e causam infecções em vários tecidos e órgãos (Kashem \& Kaplan, 2016; Zhai et al., 2021).

C. albicans tem sido descrita como a espécie mais prevalente em infecções, no entanto, outras espécies de Candida por mecanismos patológicos e epidemiológicos também se destacam pela patogenicidade e apresentam uma resistência emergente a agentes antifúngicos como C. tropicalis, C. parapsilosis e C. guilliermondii (Cordeiro et al., 2013; Brilhante et al., 2014). Outra preocupação é o surgimento de novas espécies como por exemplo C. auris descoberta em 2009 e que se apresenta com distribuição cosmopolita, associada a quadro de doença invasiva com alta mortalidade devido a um alto nível de transmissibilidade, resistência a múltiplas drogas e persistência no ambiente (Vila et al., 2020; Chakrabarti \& Singh, 2020).

Indiscutivelmente, o gênero Candida possui grande relevância na saúde humana e animal, porém o diagnóstico dessas leveduras laboratorialmente nem sempre é realizado de maneira rápida e precisa, assim o atraso diagnóstico pode aumentar o tempo de tratamento bem como do risco de morte ao paciente (Van de Groep et al., 2018). Dessa forma, técnicas moleculares são uma ferramenta útil para a correta identificação dessas leveduras e para a caracterização de novas espécies. A identificação exata de uma espécie garante também a eficácia dos resultados obtidos no teste de susceptibilidade (Clinical Laboratory and Standards Institute, 2012; Malek, Paluchowska, Bogusz \& Budak, 2017; Dudiuk et al., 2017).

Embora a terapia antifúngica para infecções associadas ao gênero Candida seja padronizada, a verificação do perfil de susceptibilidade é recomendada devido ao aparecimento de cepas resistentes aos antifúngicos. No entanto, essa técnica nem sempre é realizada na rotina, pelo alto custo, principalmente em países emergentes como o Brasil (Denning \& Hope, 2010). No 
Brasil, os principais antifúngicos utilizados no tratamento de Candida sp. são os azólicos como fluconazol, itraconazol e voriconazol. Estes são antifúngicos de amplo espectro e não apresentam toxicidade pronunciada no hospedeiro. Embora esses compostos sejam amplamente usados, a resistência já foi relatada em isolados de Candida de animais selvagens e domésticos (Brilhante et al., 2014; Sidrim et al., 2016).

A diversidade de Candida spp. em animais silvestres e domésticos no Brasil, e sua suscetibilidade aos antifúngicos ainda é pouco estudada, o que dificulta o entendimento das espécies e a ocorrência dessas na região, bem como o tratamento mais adequado. O objetivo deste trabalho foi realizar o primeiro estudo de Candida spp. em animais domésticos e selvagens no estado de Mato Grosso a fim de verificar a diversidade dessas leveduras e avaliar o perfil de susceptibilidade a antifúngicos.

\section{Metodologia}

\subsection{Comitê de Ética}

Esta pesquisa foi aprovada pelo Comitê de Ética e Experimentação Animal da Universidade Federal de Mato Grosso (Mato Grosso, Brasil), processo número: 23108.161697/2016-67.

\subsection{Isolamento}

Os isolados foram obtidos de materiais recebidos e processados no Laboratório de Microbiologia Veterinária da Universidade Federal de Mato Grosso - UFMT (Cuiabá, Mato Grosso - Brasil) e foram coletados de 5 espécies de animais domésticos e 11 espécies de animais silvestres. Ao todo, os isolados foram de 13 sítios de coletas, entre eles: pelos, fezes, leite, urina, líquido cavitário, fígado, linfonodos, suabe nasal, suabe ocular, suabe oral, suabe otológico, inglúvio e pulmão. As leveduras foram inicialmente isoladas e caracterizadas morfológica e tintorialmente como Candida spp. de acordo com Quinn et al. (2011).

\subsection{Extração de DNA}

As leveduras foram cultivadas em caldo Sabouraud por $12 \mathrm{~h}$ a $37^{\circ} \mathrm{C}$, com agitação. As culturas $(2 \mathrm{~mL})$ foram centrifugadas e os pellets ressuspensos em $1 \mathrm{~mL}$ de tampão de lise (100 mmol de NaCl, 25 mmol de EDTA, 100 mmol de Tris$\mathrm{HCl}, \mathrm{pH}$ 8,0 e 0,5\% de SDS) contendo 0,05 gramas de pérola de vidro para a extração de DNA genômico de acordo com Del Poeta et al., 1999. O DNA obtido foi ressuspenso em $50 \mu \mathrm{L}$ de água ultrapura, quantificado, diluído a $10 \mathrm{ng} / \mu \mathrm{L}$ e armazenado a $-20^{\circ} \mathrm{C}$ até o uso.

\subsection{Identificação molecular}

O protocolo de amplificação de PCR (Reação em Cadeia da Polimerase) utilizou os oligonucleotideos ITS4 (5TCCTCCGCTTATTGATATGC-3) e ITS5 (5-GGAAGTAAAAGTCGTAACAAGG-3) (White, Bruns \& Taylor, 1990), que amplificam as regiões ITS1 e ITS2 fúngicas, resultando em um fragmento de aproximadamente 500pb. As reações foram realizadas utilizando o sistema ProFlex PCR (Life Technologies) em um volume final de 25 $\mu$ L [10ng de DNA, 1U de Taq DNA Polimerase (Sigma), 0,2mmol dNTPs, 2,0 mmol $\mathrm{MgCl}_{2}, 2,5 \mu \mathrm{L}$ de tampão de PCR 10x (200mM Tris - HCl, pH 8,4, $500 \mathrm{mmol} \mathrm{KCl}$ ) e $20 \mathrm{pmol}$ de cada oligonucleotídeo].

Os parâmetros dos ciclos de PCR foram: $95^{\circ} \mathrm{C}$ durante 10 min; seguido por 40 ciclos de $95^{\circ} \mathrm{C}$ por $15 \mathrm{~s}, 53^{\circ} \mathrm{C}$ por $30 \mathrm{~s} \mathrm{e}$ $72^{\circ} \mathrm{C}$ por 30s; com uma extensão final a $72^{\circ} \mathrm{C}$ por $5 \mathrm{~min}$. Água ultrapura foi usada como controle negativo, e DNA de $C$. glabrata, confirmado por sequenciamento, foi usado como controle positivo. Os produtos de PCR foram analisados em gel de agarose $(1,0 \%)$ a $10 \mathrm{~V} / \mathrm{cm}$, corados com GelRed (Biotium) e visualizados usando fotodocumentador ChemiDoc XRS com o 
software ImageLab. Posteriormente, foram purificados usando o kit GFX PCR DNA (GE Healthcare), de acordo com as instruções do fabricante.

As amostras foram sequenciadas usando um sequenciador automático ABI3500 (Applied Biosystems), também de acordo com as instruções do fabricante. As sequências obtidas foram comparadas com sequências depositadas na base de dados de DNA usando o programa BLAST do National Center for Biotechnology Information (NCBI) (https://www.ncbi.nlm.nih.gov/BLAST/Blast.cgi). As sequências obtidas foram depositadas no GenBank sob a identificação MF797705 a MF797783.

\subsection{Teste de susceptibilidade}

A técnica de microdiluição em caldo foi utilizada para avaliar a suscetibilidade in vitro aos seguintes antifúngicos com as respectivas faixas de concentração utilizadas em nove diluições em série: caspofungina $\left(0,00781\right.$ a $\left.4 \mu \mathrm{g} \mathrm{ml}^{-1}\right)$, fluconazol $\left(0,25\right.$ a $\left.128 \mu \mathrm{g} \mathrm{ml}^{-1}\right)$, voriconazol $\left(0,00781\right.$ a $\left.4 \mu \mathrm{g} \mathrm{ml}^{-1}\right)$, anfotericina $\mathrm{B}\left(0,0625\right.$ a $\left.32 \mu \mathrm{g} \mathrm{ml}^{-1}\right)$, nistatina $\left(0,25\right.$ a $\left.128 \mu \mathrm{g} \mathrm{ml} l^{-1}\right) \mathrm{e}$ itraconazol $\left(0,03125\right.$ a $\left.16 \mu \mathrm{g} \mathrm{ml}^{-1}\right)$ (Sigma-Aldrich, St. Louis, MO).

Os isolados foram cultivados em tubos estéreis com ágar Sabouraud dextrose, incubados a $35^{\circ} \mathrm{C}$ por $24 \mathrm{~h}$ e ressuspensos em $5 \mathrm{~mL}$ de solução salina estéril na concentração de $0,85 \%$. A suspensão resultante foi agitada em vórtex durante 15 segundos e as densidades celulares, ajustadas com espectrofotômetro, acrescentando-se solução salina suficiente para obter a transmitância equivalente de uma solução-padrão da escala de McFarland 0,5, em comprimento de onda de 530nm. A suspensão-padrão foi ajustada para $1 \times 10^{6}$ a $5 \times 10^{6}$ células por $\mathrm{mL}$. A suspensão de trabalho foi produzida fazendo-se uma diluição 1:50 seguida de uma diluição de 1:20 da suspensão-padrão com meio líquido RPMI 1640, resultando em concentração de $1,5 \pm 1,0 \times 10^{3}$ células por $\mathrm{mL}$.

O teste de microdiluição foi realizado em placas estéreis, descartáveis, com 96 poços. Alíquotas dos antifúngicos (duas vezes concentradas) serão dispensados na primeira coluna, e a diluição seriada foi realizada em volumes de $100 \mu 1$ com pipeta multicanal a partir da segunda coluna (2 a 10). As fileiras 11 e 12 representaram, respectivamente, os controles negativos e positivos. Cada poço da placa de microdiluição foi inoculado com $100 \mu \mathrm{L}$ da correspondente suspensão do inóculo. Os poços de controle de crescimento (controles positivos) continham $100 \mu \mathrm{L}$ de meio estéril, isento de antifúngicos, inoculados com $100 \mu \mathrm{L}$ das suspensões dos inóculos.

As placas de microdiluição foram incubadas a $35^{\circ} \mathrm{C}$ e as concentrações inibitórias mínimas determinadas após 24 e $48 \mathrm{~h}$ de incubação. A leitura foi realizada com base na inibição do crescimento do fungo, comparado ao seu controle positivo. Para interpretação dos resultados foram considerados os critérios definidos nos protocolos internacionais M27-A3 e M27-S3, ambos especificados pelo Clinical Laboratory and Standards Institute (CLSI, 2012) (Inácio et al., 2021). Os valores de referência utilizados estão resumidos na Tabela 1. 
Tabela 1. Interpretação dos valores da Concentração Inibitória Mínima dos antifúngicos testados.

\begin{tabular}{|c|c|c|c|c|}
\hline \multirow[b]{2}{*}{ Espécies de Candida } & \multirow[b]{2}{*}{ Antifúngico } & \multicolumn{3}{|c|}{ Concentração Inibitória Mínima $(\mu \mathrm{g} / \mathrm{mL})$} \\
\hline & & Susceptibilidade & SDD & Resistência \\
\hline \multirow{6}{*}{ C. glabrata } & Caspofungina & $\leq 0,125$ & 0,25 & $\geq 0,5$ \\
\hline & Fluconazol & $\leq 8$ & $16-36$ & $\geq 64$ \\
\hline & Voriconazol & $\leq 1$ & 2 & $\geq 4$ \\
\hline & Anfotericina B & $\leq 1$ & - & $\geq 1$ \\
\hline & Nistatina & $\leq 8$ & $16-36$ & $\geq 64$ \\
\hline & Itraconazol & $\leq 0,125$ & $0,25-0,5$ & $\geq 1$ \\
\hline \multirow{6}{*}{ C. parapsilosis } & Caspofungina & $\leq 2$ & 4 & $\geq 8$ \\
\hline & Fluconazol & $\leq 2$ & 4 & $\geq 8$ \\
\hline & Voriconazol & $\leq 0,25$ & 0.5 & $\geq 1$ \\
\hline & Anfotericina B & $\leq 1$ & - & $\geq 1$ \\
\hline & Nistatina & $\leq 8$ & $16-32$ & $\geq 64$ \\
\hline & Itraconazol & $\leq 0,125$ & $0,25-0,5$ & $\geq 1$ \\
\hline \multirow{6}{*}{ C. tropicalis } & Caspofungina & $\leq 0,25$ & 0,5 & $\geq 1$ \\
\hline & Fluconazol & $\leq 2$ & 4 & $\geq 8$ \\
\hline & Voriconazol & $\leq 0,125$ & 0,5 & $\geq 1$ \\
\hline & Anfotericina B & $\leq 1$ & - & $\geq 1$ \\
\hline & Nistatina & $\leq 8$ & $16-32$ & $\geq 64$ \\
\hline & Itraconazol & $\leq 0,125$ & $0,25-0,5$ & $\geq 1$ \\
\hline
\end{tabular}

SDD = Sensível Dose Dependente. Fonte: Autores adaptado de Clinical e Laboratory Standards Institute (CLSI).

\subsection{Análise estatística}

A associação entre os sítios de coleta e o isolado de Candida spp. foram avaliados pelo teste Qui-quadrado, por meio do Software R (R-3.0.2). As diferenças foram consideradas significativas quando $\mathrm{p}<0,05$.

\section{Resultados}

No total, 79 isolados de Candida foram obtidos, a maioria deles $(62 \%$; 49/79) eram de animais domésticos e 38\% (30/79) eram de animais selvagens. Os hospedeiros com os respectivos sítios de lesão e as espécies de Candida isoladas estão listados na Tabela 2 . 
Tabela 2. Lista completa das espécies de Candida isoladas com seus respectivos hospedeiros e sítio de coleta.

\begin{tabular}{|c|c|c|c|c|}
\hline $\begin{array}{c}\text { Número da } \\
\text { amostra }\end{array}$ & Hospedeiro - Nome Científico & $\begin{array}{c}\text { Hospedeiro - Nome } \\
\text { popular }\end{array}$ & Sítio de coleta & $\begin{array}{c}\text { Espécie de Candida } \\
\text { isolada }\end{array}$ \\
\hline 1 & Alouatta caraya & Bugio-preto & Fezes & Candida glabrata \\
\hline 2 & Alouatta caraya & Bugio-preto & Pulmão & Candida glabrata \\
\hline 3 & Anodorhynchus hyacinthinus & Arara-azul-grande & Suabe oral & Candida parapsilosis \\
\hline 4 & Anodorhynchus hyacinthinus & Arara-azul-grande & Suabe oral & Candida parapsilosis \\
\hline 5 & Anodorhynchus hyacinthinus & Arara-azul-grande & Pulmão & Candida glabrata \\
\hline 6 & Anodorhynchus hyacinthinus & Arara-azul-grande & Suabe oral & Candida albicans \\
\hline 7 & Bos taurus & Bovino & Leite & Candida rugosa \\
\hline 8 & Bos taurus & Bovino & Leite & Candida rugosa \\
\hline 9 & Bos taurus & Bovino & Leite & Candida rugosa \\
\hline 10 & Bos taurus & Bovino & Suabe otológico & Candida parapsilosis \\
\hline 11 & Bos taurus & Bovino & Suabe otológico & Candida orthopsilosis \\
\hline 12 & Bos taurus & Bovino & Fígado & Candida glabrata \\
\hline 13 & Bos taurus & Bovino & Fígado & Candida tropicalis \\
\hline 14 & Bos taurus & Bovino & Leite & Candida tropicalis \\
\hline 15 & Bos taurus & Bovino & Leite & Candida parapsilosis \\
\hline 16 & Bos taurus & Bovino & Leite & Candida rugosa \\
\hline 17 & Canis lupus familiaris & Cachorro & Suabe nasal & Candida parapsilosis \\
\hline 18 & Canis lupus familiaris & Cachorro & Pelo & Candida parapsilosis \\
\hline 19 & Canis lupus familiaris & Cachorro & Suabe otológico & Candida tropicalis \\
\hline 20 & Canis lupus familiaris & Cachorro & Suabe otológico & Candida rugosa \\
\hline 21 & Canis lupus familiaris & Cachorro & Suabe otológico & Candida rugosa \\
\hline 22 & Canis lupus familiaris & Cachorro & Suabe oral & Candida tropicalis \\
\hline 23 & Canis lupus familiaris & Cachorro & Pelo & Candida albicans \\
\hline 24 & Canis lupus familiaris & Cachorro & Suabe otológico & Candida albicans \\
\hline 25 & Canis lupus familiaris & Cachorro & Suabe otológico & Candida glabrata \\
\hline 26 & Canis lupus familiaris & Cachorro & Pelo & Candida glabrata \\
\hline 27 & Canis lupus familiaris & Cachorro & Suabe otológico & Candida tropicalis \\
\hline 28 & Canis lupus familiaris & Cachorro & Suabe otológico & Candida rugosa \\
\hline 29 & Canis lupus familiaris & Cachorro & Suabe otológico & Candida rugosa \\
\hline 30 & Canis lupus familiaris & Cachorro & Suabe otológico & Candida rugosa \\
\hline 31 & Canis lupus familiaris & Cachorro & Suabe otológico & Candida rugosa \\
\hline 32 & Canis lupus familiaris & Cachorro & Pelo & Candida parapsilosis \\
\hline 33 & Canis lupus familiaris & Cachorro & Suabe otológico & Candida rugosa \\
\hline 34 & Canis lupus familiaris & Cachorro & Suabe otológico & Candida rugosa \\
\hline 35 & Canis lupus familiaris & Cachorro & Fezes & Candida albicans \\
\hline 36 & Canis lupus familiaris & Cachorro & Líquido cavitário & Candida glabrata \\
\hline 37 & Canis lupus familiaris & Cachorro & Suabe otológico & Candida rugosa \\
\hline 38 & Canis lupus familiaris & Cachorro & Suabe otológico & Candida rugosa \\
\hline 39 & Canis lupus familiaris & Cachorro & Linfonodo & Candida albicans \\
\hline 40 & Canis lupus familiaris & Cachorro & Suabe otológico & Candida parapsilosis \\
\hline
\end{tabular}


Research, Society and Development, v. 10, n. 10, e264101018541, 2021

(CC BY 4.0) | ISSN 2525-3409 | DOI: http://dx.doi.org/10.33448/rsd-v10i10.18541

\begin{tabular}{|c|c|c|c|c|}
\hline 41 & Canis lupus familiaris & Cachorro & Suabe otológico & Candida parapsilosis \\
\hline 42 & Canis lupus familiaris & Cachorro & Suabe otológico & Candida rugosa \\
\hline 43 & Canis lupus familiaris & Cachorro & Urina & Candida parapsilosis \\
\hline 44 & Canis lupus familiaris & Cachorro & Suabe otológico & Candida rugosa \\
\hline 45 & Canis lupus familiaris & Cachorro & Suabe otológico & Candida parapsilosis \\
\hline 46 & Canis lupus familiaris & Cachorro & Suabe otológico & Candida rugosa \\
\hline 47 & Canis lupus familiaris & Cachorro & Suabe otológico & Candida tropicalis \\
\hline 48 & Canis lupus familiaris & Cachorro & Suabe otológico & Candida parapsilosis \\
\hline 49 & Canis lupus familiaris & Cachorro & Suabe otológico & Candida rugosa \\
\hline 50 & Cariama cristata & Seriema & Suabe otológico & Candida heveicola \\
\hline 51 & Equus caballus & Cavalo & Pelo & Candida parapsilosis \\
\hline 52 & Equus caballus & Cavalo & Fígado & Candida rugosa \\
\hline 53 & Felis catus & Gato & Suabe nasal & Candida parapsilosis \\
\hline 54 & Felis catus & Gato & Pelo & Candida haemulonii \\
\hline 55 & Felis catus & Gato & Suabe ocular & Candida parapsilosis \\
\hline 56 & Mazama gouazoubira & Veado catingueiro & Pulmão & Candida pararugosa \\
\hline 57 & Myrmecophaga tridactyla & Tamanduá bandeira & Suabe oral & Candida albicans \\
\hline 58 & Myrmecophaga tridactyla & Tamanduá bandeira & Suabe oral & Candida albicans \\
\hline 59 & Nasua nasua & Quati & Fezes & Candida rugosa \\
\hline 60 & Nasua nasua & Quati & Suabe oral & Candida quercitrusa \\
\hline 61 & Nasua nasua & Quati & Fezes & Candida tropicalis \\
\hline 62 & Nasua nasua & Quati & Fezes & Candida tropicalis \\
\hline 63 & Nasua nasua & Quati & Fezes & Candida tropicalis \\
\hline 64 & Nasua nasua & Quati & Pelo & Candida albicans \\
\hline 65 & Nasua nasua & Quati & Líquido cavitário & Candida metapsilosis \\
\hline 66 & Nymphicus hollandicus & Calopsita & Inglúvio & Candida glabrata \\
\hline 67 & Nymphicus hollandicus & Calopsita & Fezes & Candida glabrata \\
\hline 68 & Nymphicus hollandicus & Calopsita & Fezes & Candida albicans \\
\hline 69 & Nymphicus hollandicus & Calopsita & Fezes & Candida albicans \\
\hline 70 & Ovis aries & Ovelha & Fezes & Candida albicans \\
\hline 71 & Panthera onca & Onça pintada & Suabe oral & Candida orthopsilosis \\
\hline 72 & Panthera onca & Onça pintada & Suabe oral & Candida michaelii \\
\hline 73 & Panthera onca & Onça pintada & Suabe oral & Candida albicans \\
\hline 74 & Pseudoplatystoma corruscans & Peixe pintado & Fezes & Candida glabrata \\
\hline 75 & Rhea americana & Ema & Fezes & Candida glabrata \\
\hline 76 & Spizaetus melanoleucus & Gavião-pato & Suabe oral & Candida rugosa \\
\hline 77 & Spizaetus melanoleucus & Gavião-pato & Fezes & Candida tropicalis \\
\hline 78 & Spizaetus melanoleucus & Gavião-pato & Fezes & Candida tropicalis \\
\hline 79 & Spizaetus melanoleucus & Gavião-pato & Fezes & Candida parapsilosis \\
\hline
\end{tabular}

Fonte: Autores. 
Os isolados foram classificados em 12 espécies diferentes com base na análise da região ITS (Tabela 3). C. albicans representou $15 \%$ (12/79) dos isolados e as espécies não-albicans representaram 85\% (67/79). C. rugosa foi a espécie mais frequentemente isolada de animais domésticos (39\% dos isolados; 19/49), seguida por C. parapsilosis (26\%; 13/49). Em animais silvestres, as espécies mais frequentemente isoladas foram C. albicans $(23 \% ; 7 / 30)$ e C. glabrata $(23 \%$; $7 / 30)$.

Tabela 3. Frequência das diferentes espécies de Candida obtidas das amostras de animais domésticos e silvestres.

\begin{tabular}{c|c|c|c}
\hline Espécie de Candida & $\begin{array}{c}\text { Animais domésticos } \\
(\mathrm{n}=49)\end{array}$ & $\begin{array}{c}\text { Animais silvestres } \\
(\mathrm{n}=30)\end{array}$ & Total \\
\hline C. rugosa & 19 & 2 & 21 \\
\hline C. parapsilosis & 13 & 3 & 16 \\
\hline C. albicans & 5 & 7 & 12 \\
\hline C. glabrata & 4 & 7 & 11 \\
\hline C. tropicalis & 6 & 5 & 11 \\
\hline C. orthopsilosis & 1 & 1 & 2 \\
\hline C. haemulonii & 1 & 1 & 1 \\
\hline C. leveicola & 0 & 1 & 1 \\
\hline C. metapsilosis & 0 & 1 & 1 \\
\hline C. michaeli & 0 & 1 & 1 \\
\hline C. pararugosa & 0 & 1 & 1 \\
\hline C. quercitrusa & 0 & & \\
\hline
\end{tabular}

n: Número total. Fonte: Autores.

Foi observada associação estatística significativa entre os locais de isolamento e as espécies de Candida. C. rugosa foi a espécie mais frequentemente detectada em suabes otológicos $(54 \% ; 14 / 26)$ e leite $(57 \%$; 4/7). C. tropicalis foi a espécie mais comumente isolada nas fezes $(35 \% ; 5 / 14)$ e $C$. albicans em suabes orais $(33 \% ; 4 / 12)$. Ao considerar o local de isolamento e as espécies de Candida de animais selvagens, foi observada associação estatística, sendo a $C$. tropicalis mais comum nas fezes (38\%; 5/13); C. albicans em suabes orais $(40 \%$; 4/10) e C. glabrata de pulmão (66\%; 2/3). Dos isolados testados, $100 \%$ foram resistentes ao itraconazol e nenhuma resistência ao voriconazol foi observada.

Nos isolados de C. glabrata não foi observada resistência aos antifúngicos: caspofungina, fluconazol, voriconazol e nistatina; onde as maiores taxas de susceptibilidade obtidas foram para caspofungina 90\% (9/10) e voriconazol (100\%; 10/10). $\mathrm{Na}$ avaliação de $C$. parapsilosis, os isolados apresentaram no teste de susceptibilidade maior susceptibilidade a caspofungina $(100 \%$; 10/10) e voriconazol e anfotericina B (90\% em ambos os casos; 9/10). Todos os isolados de C. tropicalis foram resistentes à caspofungina e itraconazol $(100 \% ; 10 / 10)$ e 50\%; (5/10) ao fluconazol e à anfotericina B, apresentando, portanto, um perfil medicamentoso multirresistente. Os dados de suscetibilidade antifúngica obtidos estão agrupados na Tabela 4. 
Tabela 4 - Perfil de suscetibilidade in vitro de Candida spp. obtidas aos antifúngicos testados.

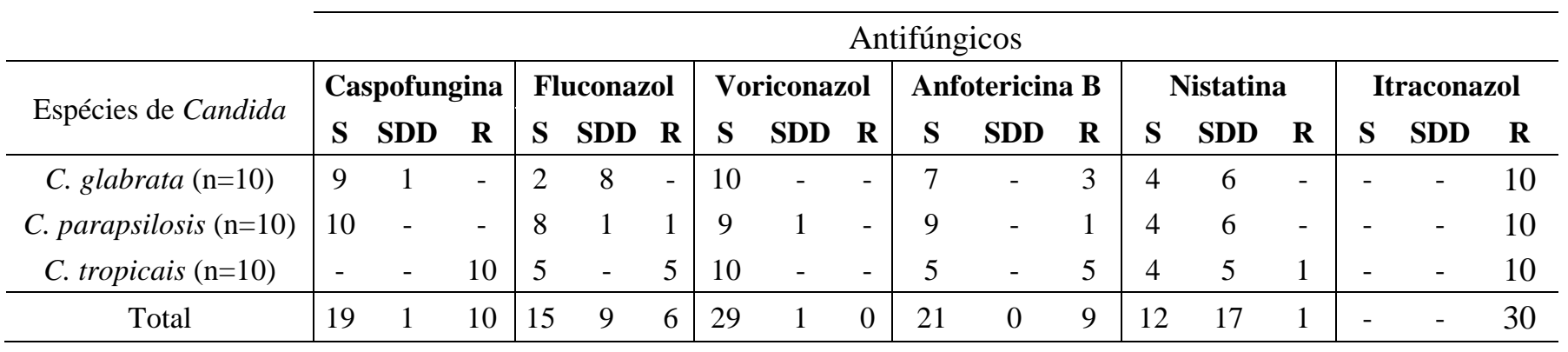

S: Sensível; SDD: Sensível dose dependente; R: Resistente; n: Número total. Fonte: Autores.

\section{Discussão}

O gênero Candida é um dos mais importantes causadores de infecções fúngicas em animais (Dworecka-Kaszak, Biegańska \& Dąbrowska, 2020). No entanto, as informações sobre a distribuição dessas leveduras em animais domésticos e silvestres no Brasil são escassas. A grande diversidade genética de espécies desse gênero dificulta o diagnóstico laboratorial e, consequentemente, o tratamento adequado e eficaz (Nejad et al., 2020).

C. albicans é a espécie de Candida mais comum em humanos (Araújo, Lopes \& Cruz, 2020) e animais (Sidrim et al., 2016). A análise de sequenciamento da região ITS realizada no presente estudo revelou que foi a terceira espécie mais isolada (15\% de todos os isolados; 12/79); C. rugosa foi a espécie mais frequentemente isolada (26\%; 21/79), seguida por $C$. parapsilosis $(20,2 \% ; 16 / 79)$. Entretanto, entre os isolados de Candida de animais silvestres, C. albicans foi a espécie mais frequentemente encontrada, junto com C. glabrata (23\% em ambos os casos; 7/30).

Alguns estudos em humanos já foram realizados no estado de Mato Grosso, Brasil. Um deles avaliou a diversidade de espécies do gênero Candida isoladas de diferentes sítios anatômicos de militares, onde C. albicans foi a espécie mais frequente (34,4\% das amostras), seguida por C. parapsilosis $(20,25 \%)$ e C. tropicalis $(13,9 \%)$. Isolados de C. rugosa não foram detectados neste estudo (Leite-Junior et al., 2011). Outro estudo realizado no estado avaliou a etiologia de candidíases nosocomiais, onde foi observado que C. albicans também foi a espécie mais identificada com 39,09\% dos casos (Yamamoto et al., 2012).

Como já foi evidenciado, a colonização de animais e humanos nesta região do Brasil por Candida spp. não segue o mesmo padrão, pois no presente estudo a espécie mais frequentemente isolada foi $C$. rugosa, seguida de $C$. parapsilosis. Podese também concluir que existe um envolvimento cada vez maior de espécies não-albicans nas infecções; isso, por sua vez, sugere sua patogenicidade crescente devido a formação de biofilmes e aumento da resistência aos antifúngicos, expandindo a capacidade de infectar e permanecer no hospedeiro (El-Kholy et al., 2021).

Em análises moleculares de Candida spp. realizados com isolados veterinários realizados na Universidade de Cornell (Ithaca, NY, EUA), C. albicans foi a espécie mais detectada (17\% de todos os isolados); entretanto, outras espécies desse gênero, quando combinadas, representaram um percentual maior de 83\%, apontando também para um aumento na incidência de espécies de Candidas não-albicans (Garner, Starr, McDonough \& Altier, 2010).

A observação de que $C$. rugosa foi a espécie mais encontrada no presente estudo pode estar associada por ter se tornado um patógeno emergente em humanos capazes de produzir fatores de virulência como as enzimas proteinase, esterase, hemolisina e biofilme (Singh et al., 2016; Peremalo et al., 2019) e em animais, está principalmente associada à mastite. $C$. rugosa já foi reconhecido como agente etiológico de mastite em 14 vacas leiteiras durante um surto de contaminação ambiental sendo isolado também da ração, água e curral, o que demonstrou sua capacidade de sobreviver em diferentes ambientes e, 
portanto, de espalhar-se mais facilmente no ambiente (Scaccabarozzi et al., 2011). No entanto, no presente estudo, C. rugosa foi associada principalmente a otite (14/21), seguido de mastite (4/21).

C. parapsilosis foi a segunda espécie mais frequentemente identificada neste estudo, encontrada em 20,25\% (16/79) dos isolados, e em suabes otológicos em 31,25\% (5/16). Está comumente associada à dermatite seborreica e é encontrada nas otites na presença ou ausência de outra levedura, Malassezia pachydermatis (Bumroongthai et al., 2016). Além de isolados otológicos, $C$. parapsilosis também foi encontrada em pelos (2/16), cavidade nasal (2/16), leite (2/16) e cavidade oral (2/16), demonstrando sua capacidade de colonizar vários órgãos e tecidos. Da mesma forma que C. rugosa, C. parapsilosis foi descrita como uma levedura emergente em infecções animais (Cordeiro et al., 2017).

Para determinação da susceptibilidade antifúngica foram testados 30 isolados, sendo 10 de cada espécie (C. glabrata, C. parapsilosis e C. tropicalis). Essas espécies foram escolhidas por serem espécies não-albicans consideradas emergentes em infecções e por estarem entre as mais frequentes, com distribuição semelhante em animais domésticos e silvestres.

O itraconazol é um dos antifúngicos mais utilizados para o tratamento da candidíase em animais, entretanto, todos os isolados testados no presente estudo foram resistentes a esse fármaco. Isso sugere uma resistência emergente a essa droga no gênero Candida. Portanto, o teste de susceptibilidade deve ser realizado para indicar qual antifúngico obterá a melhor resposta contra o agente fúngico testado, aumentando assim, a probabilidade de sucesso da terapia farmacológica instituída por meio dos resultados obtidos (Pfaller et al., 2012; Brilhante et al., 2018).

Nenhum dos isolados testados foi resistente ao voriconazol, resultado semelhante encontrado durante a avaliação do perfil de suscetibilidade de isolados de Candida do trato genital de fêmeas dromedárias (Camelus dromedarius) no Irã (Sharifzadeh, Soltani \& Shokri, 2015).

Os isolados de C. tropicalis foram resistentes a múltiplos agentes antifúngicos. Essa observação já foi relatada no Nordeste brasileiro e, portanto, deve ser monitorada (Zuza-Alvez et al., 2016). Esta levedura representa um risco para a saúde humana e animal devido ao seu potencial patogênico (Hernández-Chávez et al., 2018) a qual também já foi relatada em surto em uma criação de matrizes suínas com quadro clínico gastrointestinal, que desencadeou a morte de $60 \%$ dos animais acometidos (Zhai et al., 2021).

\section{Conclusão}

Estre estudo contribuiu para o entendimento da ocorrência e do perfil de susceptibilidade a antifúngicos de Candida spp. no estado de Mato Grosso - Brasil, onde ficou evidente que isolados de animais silvestres e domésticos diferem aos de humanos já descritos por outros autores. A alta resistência ao itraconazol alerta que o tratamento continuado com esse medicamento pode se tornar ineficaz. A resistência a múltiplos fármacos observada em $C$. tropicalis sinaliza para um risco eminente de candidíase sem opções de tratamento. Este é o primeiro estudo de Candida spp. em animais no estado de Mato Grosso e encoraja a execução de novas pesquisas relacionadas a verificação da presença de fatores de virulência e acompanhamento do perfil de susceptibilidade aos antifúngicos de espécies de Candida em animais domésticos e silvestres como estratégia de entendimento epidemiológico que ajudam a direcionar o correto tratamento.

\section{Referências}

Araújo, I. M., Lopes, L. P. \& Cruz, C. M. (2020). Caracterização sistemática da resposta imune à infecção por Candida. Brazilian Journal of health Review, 3(2), 3788-3803. https://10.34119/bjhrv3n2-203.

Brilhante, R., Rodrigues, T., Castelo-Branco, D., Teixeira, C., Macedo, R. B., Bandeira, S. P., Pereira de Alencar, L., Monteiro, A. J., Cordeiro, R. A., Bandeira, T., Moreira, J., Sidrim, J., \& Rocha, M. (2014). Antifungal susceptibility and virulence attributes of animal-derived isolates of Candida parapsilosis complex. Journal of medical microbiology, 63(Pt 11), 1568-1572. https://doi.org/10.1099/jmm.0.076216-0. 
Bumroongthai, K., Chetanachan, P., Niyomtham, W., Yurayart, C., \& Prapasarakul, N. (2016). Biofilm production and antifungal susceptibility of co-cultured Malassezia pachydermatis and Candida parapsilosis isolated from canine seborrheic dermatitis. Medical mycology, 54(5), 544-549. https://doi.org/10.1093/mmy/myw002.

Chakrabarti, A., \& Singh, S. (2020). Multidrug-resistant Candida auris: an epidemiological review. Expert review of anti-infective therapy, 18(6), 551-562. https://doi.org/10.1080/14787210.2020.1750368.

Clinical Laboratory and Standards Institute (CLSI) (2012). Reference method for broth dilution antifungal susceptibility testing yeasts. (Document M27-S4). $4^{\text {th }}$ Edition. Wayne, PA.

Cordeiro, R., Bittencourt, P. V., Brilhante, R. S., Teixeira, C. E., Castelo-Branco, D., Silva, S. T., De Alencar, L. P., Souza, E. R., Bandeira, T., Monteiro, A. J., Sidrim, J. J., \& Rocha, M. F. (2013). Species of Candida as a component of the nasal microbiota of healthy horses. Medical mycology, 51(7), 731-736. https://doi.org/10.3109/13693786.2013.777858.

Cordeiro, R. A., Sales, J. A., Castelo-Branco, D., Brilhante, R., Ponte, Y. B., Dos Santos Araújo, G., Mendes, P., Pereira, V. S., Alencar, L. P., Pinheiro, A. Q., Sidrim, J., \& Rocha, M. (2017). Candida parapsilosis complex in veterinary practice: A historical overview, biology, virulence attributes and antifungal susceptibility traits. Veterinary microbiology, 212, 22-30. https://doi.org/10.1016/j.vetmic.2017.07.031.

Del Poeta, M., Toffaletti, D. L., Rude, T. H., Dykstra, C. C., Heitman, J., \& Perfect, J. R. (1999). Topoisomerase I is essential in Cryptococcus neoformans: role In pathobiology and as an antifungal target. Genetics, 152(1), 167-178.

Denning, D. W., \& Hope, W. W. (2010). Therapy for fungal diseases: opportunities and priorities. Trends in microbiology, 18(5), 195-204. https://doi.org/10.1016/j.tim.2010.02.004.

Dudiuk, C., Morales-López, S. E., Podesta, V., Macedo, D., Leonardelli, F., Vitale, R. G., Tosello, M. E., Cabeza, M. S., Biasoli, M., Gamarra, S., \& GarciaEffron, G. (2017). Multiplex PCR designed to differentiate species within the Candida glabrata complex. Revista iberoamericana de micologia, 34(1), 43-45. https://doi.org/10.1016/j.riam.2016.04.007.

Dworecka-Kaszak, B., Biegańska, M. J., \& Dąbrowska, I. (2020). Occurrence of various pathogenic and opportunistic fungi in skin diseases of domestic animals: a retrospective study. BMC veterinary research, 16(1), 248. https://doi.org/10.1186/s12917-020-02460-x.

El-Kholy, M. A., Helaly, G. F., El Ghazzawi, E. F., El-Sawaf, G., \& Shawky, S. M. (2021). Virulence Factors and Antifungal Susceptibility Profile of $C$. tropicalis Isolated from Various Clinical Specimens in Alexandria, Egypt. Journal of fungi (Basel, Switzerland), 7(5), 351. https://doi.org/10.3390/jof7050351.

Garner, C. D., Starr, J. K., McDonough, P. L., \& Altier, C. (2010). Molecular identification of veterinary yeast isolates by use of sequence-based analysis of the D1/D2 region of the large ribosomal subunit. Journal of clinical microbiology, 48(6), 2140-2146. https://doi.org/10.1128/JCM.02306-09.

Hernández-Chávez, M. J., Franco, B., Clavijo-Giraldo, D. M., Hernández, N. V., Estrada-Mata, E., \& Mora-Montes, H. M. (2018). Role of protein phosphomannosylation in the Candida tropicalis macrophage interaction. FEMS yeast research, 18(5), 10.1093/femsyr/foy053. https://doi.org/10.1093/femsyr/foy053.

Inácio, C. P., Beserra, F. G., Soares, C. R. P., Romaguera, L. M. D., Araújo, P. S. R., Buonafina, M. D. S., Araújo Neto, L. N., Santos, D. C. dos \& Neves, R.P. (2021). Epidemiologia e padrões de suscetibilidade antifúngica de espécies de Candida em hospitais terciários: Atualização sobre tendências regionais. Research, Society and Development. 10, 4 (abr. 2021), e59810414462. https://doi.org/10.33448/rsd-v10i4.14462.

Kashem, S. W., \& Kaplan, D. H. (2016). Skin Immunity to Candida albicans. Trends in immunology, 37(7), 440-450. https://doi.org/10.1016/j.it.2016.04.007.

Leite-Júnior, D. P., Yamamoto, A. C., Martins, E. R., Teixeira, A. F., \& Hahn, R. C. (2011). Species of Candida isolated from anatomically distinct sites in military personnel in Cuiabá, Mato Grosso, Brazil. Anais brasileiros de dermatologia, 86(4), 675-680. https://doi.org/10.1590/s0365-05962011000400008.

Malek, M., Paluchowska, P., Bogusz, B., \& Budak, A. (2017). Molecular characterization of Candida isolates from intensive care unit patients, Krakow, Poland. Revista iberoamericana de micologia, 34(1), 10-16. https://doi.org/10.1016/j.riam.2016.03.005.

Nejad, E., Ghasemi Nejad Almani, P., Mohammadi, M. A., \& Salari, S. (2020). Molecular identification of Candida isolates by Real-time PCR-highresolution melting analysis and investigation of the genetic diversity of Candida species. Journal of clinical laboratory analysis, $34(10)$, e23444. https://doi.org/10.1002/jcla.23444.

Peremalo, T., Madhavan, P., Hamzah, S., Than, L., Wong, E. H., Nasir, M., Chong, P. P., \& Ng, K. P. (2019). Antifungal susceptibilities, biofilms, phospholipase and proteinase activities in the Candida rugosa complex and Candida pararugosa isolated from tertiary teaching hospitals. Journal of medical microbiology, 68(3), 346-354. https://doi.org/10.1099/jmm.0.000940.

Pfaller, M. A., Espinel-Ingroff, A., Canton, E., Castanheira, M., Cuenca-Estrella, M., Diekema, D. J., Fothergill, A., Fuller, J., Ghannoum, M., Jones, R. N., Lockhart, S. R., Martin-Mazuelos, E., Melhem, M. S., Ostrosky-Zeichner, L., Pappas, P., Pelaez, T., Peman, J., Rex, J., \& Szeszs, M. W. (2012). Wild-type MIC distributions and epidemiological cutoff values for amphotericin B, flucytosine, and itraconazole and Candida spp. as determined by CLSI broth microdilution. Journal of clinical microbiology, 50(6), 2040-2046. https://doi.org/10.1128/JCM.00248-12.

Quinn, P. J., Markey, B. K., Leonard, F. C., Hartigan, P., Fanning, S., \& Fitzpatrick, E. S. (2011). Veterinary Microbiology and Microbial Disease. 3 ed. Artmed.

Scaccabarozzi, L., Locatelli, C., Pisoni, G., Manarolla, G., Casula, A., Bronzo, V., \& Moroni, P. (2011). Short communication: Epidemiology and genotyping of Candida rugosa strains responsible for persistent intramammary infections in dairy cows. Journal of dairy science, 94(9), 4574-4577. https://doi.org/10.3168/jds.2011-4294.

Sharifzadeh, A., Soltani, M., \& Shokri, H. (2015). Evaluation of virulence factors and antifungal susceptibility patterns of different Candida species isolated from the female camel (Camelus dromedarius) genital tract. Mycoses, 58(8), 478-484. https://doi.org/10.1111/myc.12345. 
Research, Society and Development, v. 10, n. 10, e264101018541, 2021

(CC BY 4.0) | ISSN 2525-3409 | DOI: http://dx.doi.org/10.33448/rsd-v10i10.18541

Sidrim, J. J., Carvalho, V. L., de Souza Collares Maia Castelo-Branco, D., Brilhante, R. S., de Melo Guedes, G. M., Barbosa, G. R., Lazzarini, S. M., Oliveira, D. C., de Meirelles, A. C., Attademo, F. L., da Bôaviagem Freire, A. C., de Aquino Pereira-Neto, W., de Aguiar Cordeiro, R., Moreira, J. L., \& Rocha, M. F. (2016). Antifungal Resistance and Virulence Among Candida spp. from Captive Amazonian manatees and West Indian Manatees: Potential Impacts on Animal and Environmental Health. EcoHealth, 13(2), 328-338. https://doi.org/10.1007/s10393-015-1090-8.

Singh, R. I., Xess, I., Mathur, P., Behera, B., Gupta, B., \& Misra, M. C. (2011). Epidemiology of candidaemia in critically ill trauma patients: experiences of a level I trauma centre in North India. Journal of medical microbiology, 60(Pt 3), 342-348. https://doi.org/10.1099/jmm.0.023739-0.

Van de Groep, K., Bos, M. P., Savelkoul, P., Rubenjan, A., Gazenbeek, C., Melchers, W., van der Poll, T., Juffermans, N. P., Ong, D., Bonten, M., Cremer, O. L., \& MARS consortium (2018). Development and first evaluation of a novel multiplex real-time PCR on whole blood samples for rapid pathogen identification in critically ill patients with sepsis. European journal of clinical microbiology \& infectious diseases: official publication of the European Society of Clinical Microbiology, 37(7), 1333-1344. https://doi.org/10.1007/s10096-018-3255-1.

Vila, T., Montelongo-Jauregui, D., Ahmed, H., Puthran, T., Sultan, A. S., \& Jabra-Rizk, M. A. (2020). Comparative Evaluations of the Pathogenesis of Candida auris Phenotypes and Candida albicans Using Clinically Relevant Murine Models of Infections. mSphere, 5(4), e00760-20. https://doi.org/10.1128/mSphere.00760-20.

White, T. J., Bruns, T., Lee, S., \& Taylor, J. (1990). Amplification and direct sequencing of fungal ribosomal RNA genes for phylogenetic. In PCR Protocols: a guide to methods and applications. Academic Press. 315-322.

Yamamoto, A. C., de Paula, C. R., Dias, L. B., Tadano, T., Martins, É. R., Amadio, J. V., \& Hahn, R. C. (2012). Epidemiological and clinical characteristics of nosocomial candidiasis in university hospitals in Cuiabá--Mato Grosso, Brazil. Revista iberoamericana de micologia,29(3), 164-168. https://doi.org/10.1016/j.riam.2012.01.001.

Zhai, L., Zhou, Y., Wu, Y., Jin, Y., Zhu, Q., Gao, S., Li, X., Sun, Z., Xiao, Y., Huang, B., \& Tian, K. (2021). Isolation and identification of Candida tropicalis in sows with fatal infection: a case report. BMC veterinary research, 17(1), 108. https://doi.org/10.1186/s12917-021-02821-0.

Zuza-Alves, D. L., de Medeiros, S. S., de Souza, L. B., Silva-Rocha, W. P., Francisco, E. C., de Araújo, M. C., Lima-Neto, R. G., Neves, R. P., Melo, A. S., \& Chaves, G. M. (2016). Evaluation of Virulence Factors In vitro, Resistance to Osmotic Stress and Antifungal Susceptibility of Candida tropicalis Isolated from the Coastal Environment of Northeast Brazil. Frontiers in microbiology, 7, 1783. https://doi.org/10.3389/fmicb.2016.01783. 